\title{
Venous Thromboembolism Risk in Asian Patients with Inflammatory Bowel Disease: A Population-Based Nationwide Inception Cohort Study
}

\author{
Su Young Kim¹, Yeon Seo Cho², Hyun-Soo Kim , Jung Kuk Lee ${ }^{3}$, Hee Man Kim, Hong Jun Park', Hyunil Kim¹, \\ Jihoon $\mathrm{Kim}^{2}$, and Dae Ryong Kang ${ }^{3}$ \\ ${ }^{1}$ Division of Gastroenterology, Department of Internal Medicine, Yonsei University Wonju College of Medicine, ${ }^{2}$ Department of \\ Medicine, Wonju Severance Christian Hospital, and ${ }^{3}$ Center of Biomedical Data Science, Yonsei University Wonju College of \\ Medicine, Wonju, Korea
}

See editorial on page 495.

\section{Article Info}

Received April 28, 2021

Revised July 27, 2021

Accepted August 3, 2021

Published online November 18, 2021

\section{Corresponding Author}

Hyun-Soo Kim

ORCID https://orcid.org/0000-0001-7190-0362

E-mail hyskim@yonsei.ac.kr

Su Young Kim and Yeon Seo Cho contributed equally to this work as first authors.
Background/Aims: Inflammatory bowel disease (IBD) is associated with the occurrence of venous thromboembolism (VTE). However, to date, there have been few studies on the risk of VTE in Asian IBD patients. We aimed to estimate the incidence of VTE in Asian IBD patients and to determine if IBD is related to increased VTE risk.

Methods: We performed a population-based cohort study between 2004 and 2015 using Korean National Health Insurance data. IBD and VTE were defined by ICD-10 codes. Incidence rates of VTE were calculated among patients with IBD and among age- and sex-matched controls. Hazard ratios were estimated using Cox regression with adjustment for multiple variables. We performed additional analyses stratifying by age, sex, Charlson comorbidity index $(\mathrm{CCl})$ score, and disease type.

Results: Among the 45,037 patients with IBD (IBD cohort) and 133,019 matched controls (nonIBD cohort) included in our analysis, 411 IBD patients and 641 controls developed VTE. The IBD cohort had a higher incidence rate ratio and risk of VTE than the non-IBD cohort (incidence rate ratio: 1.92 and hazard ratio: 1.93). Older age, female sex, higher $\mathrm{CCl}$ scores, cardiovascular disease, chronic kidney disease, use of steroids, and hospitalization were significant risk factors for VTE in patients with IBD.

Conclusions: The IBD patients in this study were approximately two times more likely to develop VTE than the non-IBD individuals. Our findings support the need for thromboprophylaxis in Asian IBD patients with various factors that further increase the risk of VTE. (Gut Liver 2022;16:555566)

Key Words: Inflammatory bowel disease; Venous thromboembolism; Prophylaxis; Population; Cohort studies

\section{INTRODUCTION}

Inflammatory bowel disease (IBD), which comprises Crohn's disease (CD) and ulcerative colitis (UC), is a chronic inflammatory disease that affects the gastrointestinal tract. ${ }^{1}$ Venous thromboembolism (VTE) is a well-studied extraintestinal manifestation of IBD, causing increased morbidity and mortality in IBD patients. ${ }^{2-5}$ Considering the increasing overall incidence and prevalence of IBD around the world, VTE related to IBD is also becoming a progressively more important issue. ${ }^{6,7}$ Several studies have demonstrated that IBD is associated with a 2 - to 3 -fold higher risk of VTE. ${ }^{3,4,8}$ Although IBD patients are at increased risk of VTE, the risk of VTE is not higher in other chronic inflammatory diseases such as rheumatoid arthritis. ${ }^{10}$ This means that VTE is a characteristic feature only in IBD patients, and eventually, the tendency of thrombosis is increased in this group of patients. Despite this clear connection, the pathogenesis of VTE in IBD is multifaceted and remains imperfectly understood. ${ }^{11}$ 
Several guidelines and consensus statements recommend antithrombotic prophylaxis for all hospitalized patients with IBD or in patients with acute severe IBD. ${ }^{12-14}$ Many studies in the past have supported the basis for these guidelines. However, due to the nature of VTE disease (low incidence and high mortality), most studies are small and retrospective. To overcome this point, several populationbased nationwide cohort studies have been conducted and published over the past decade. ${ }^{3,4,9,15-19}$ Nevertheless, most of the previous studies have several limitations, such as a relatively small number of patients, ${ }^{3,9,17}$ a short follow-up period, ${ }^{15,16,18}$ or targeting only patients in specific situations (hospitalization, pediatrics, or use of steroids/biologics). ${ }^{9,15,16,18,19}$ Moreover, most studies of VTE have been focused on Western IBD patients, and only one study on Asian IBD patients has been published. ${ }^{17}$ The incidence of IBD is gradually increasing in Asia, and it can no longer be regarded as a disease that occurs primarily in the West. ${ }^{20-23}$ Even more worrisome, only a handful of clinicians in Asian countries are reported to implement appropriate VTE prophylaxis for inpatients with IBD. ${ }^{24}$ VTE is comparatively rare in the Asian population compared to Western populations, ${ }^{25,26}$ and the exact incidence and risk factors of VTE in Asian IBD patients are not known. Also, there have been no previous studies conducted at the population level. Therefore, we aimed to evaluate the incidence and risk factors of VTE in Asian IBD patients in a population-based nationwide cohort setting.

\section{MATERIALS AND METHODS}

\section{Data source}

This study used a nationwide, population-based database from the Korean National Health Insurance System (NHIS). The NHIS is single public health insurance service and has collected health care information from $97 \%$ of the Korean population. ${ }^{27,28}$ The database includes information about patient demographics, prescriptions, disease diagnoses, procedures, and hospitalization records. All IBD patients are asked to ensure that their diagnosis is confirmed by qualified doctors through systematized diagnostic criteria distributed by the NHIS. These procedures are managed and supervised by medical institutions and the NHIS. In addition, various studies have been conducted on IBD patients using NHIS and a lot of data have already been accumulated in making an operational definition for IBD patients in Korea. ${ }^{28-30}$ Thus, codes registered as IBD in Korea are very reliable. All patient information was deidentified before data processing to comply with the regulations of the Health Insurance Portability and Account- ability Act and informed consent was waived. This study was approved by the Institutional Review Board of Wonju Severance Christian Hospital, Wonju, Korea (IRB number: CR312044).

\section{Study population}

This nationwide cohort study was performed using the NHIS database from 2004 to 2015. The platform and details of the data profile in the NHIS database have been reported in previous studies. ${ }^{31,32}$ Patients with IBD were identified using International Classification of Diseases 10th revision (ICD-10) codes accompanied by at least one claim for IBD-specific medications. ${ }^{29}$ According to the recently published nationwide validation study of IBD, our method demonstrated the highest sensitivity and specificity for operational definition of IBD. ${ }^{30}$ The ICD-10 codes for $\mathrm{CD}$ and $\mathrm{UC}$ are $\mathrm{K} 50$ and $\mathrm{K} 51$, respectively. Medications for IBD include 5-aminosalicylic acid, immune modulators (azathioprine, methotrexate, or 6-mercaptopurine), and anti-tumor necrosis factor- $\alpha$ agents (infliximab or adalimumab). Patients with a history of IBD during a washout period from January 2004 to December 2005 were excluded, along with patients with a history of VTE from 2004 to the time of first diagnosis of IBD (index date). Patients newly diagnosed with IBD between 2006 and 2015 were defined as the IBD cohort. For the control group, data were randomly extracted from the general population (people with no history of IBD) and matched by age and sex at a 1:3 ratio for the same index date. Randomization for control selection was conducted using a program in SAS version 9.4 (SAS Institute Inc, Cary, NC, USA). The matched control group was considered the non-IBD cohort.

\section{Study variables and end points}

We collected demographic data from the study population (age, sex, living area, income, and Charlson comorbidity index [CCI] score), along with data on any history of abdominal surgery, emergency room visits or hospitalization history, comorbidities, and medications. We used ICD-10 codes for all comorbidities that could be extracted from the NHIS (hypertension, diabetes mellitus, malignancy, cardiovascular disease, atrial fibrillation, heart failure, cerebrovascular disease, and chronic kidney disease). We also collected information on medications including 5 -aminosalicylic acid, steroids, thiopurines, anti-tumor necrosis factor- $\alpha$ agents, aspirin, clopidogrel, warfarin, and new oral anticoagulants.

The end point of this study was newly diagnosed VTE during the follow-up period in the IBD and non-IBD cohorts, defined as a medical code related to the diagnosis of deep vein thrombosis (I80 or I82) or pulmonary embolism 
(I26) between 2006 and 2015. We analyzed the information available from the NHIS including data regarding each subject's VTE diagnosis and the date of diagnosis. Subjects diagnosed with VTE before the follow-up period (or before IBD diagnosis) were excluded from the final analysis. Subjects in both cohorts were followed from the index date to December 2015. During follow-up, the number of subjects without newly developed VTE were counted on the last day of follow-up or the death date.

\section{Statistical analysis}

The categorical baseline characteristics of the participants are expressed as numbers (\%). The incidence rates (IRs) of VTE were calculated as the number of incident cases divided by the follow-up period and presented as incident cases per 1,000 person-years. IRs were also stratified by disease type (CD or UC), age group (0-19, 20-39, $40-59$, and $>59$ years), sex, living area, income, and CCI score. Using the IRs of both cohorts, we calculated IR ratios (IRRs) with 95\% confidence intervals (CIs). hazard ratios (HRs) for the risk of VTE based on the presence of IBD were calculated after adjusting for covariates using Cox proportional hazard regression analysis. All statistical tests were two-tailed, and a p-value $<0.05$ was considered to denote statistical significance. Analyses were performed in SAS version 9.4 (SAS Institute Inc.).

\section{RESULTS}

Between January 2006 and December 2015, we identified 45,402 patients who were diagnosed with IBD for the first time. Of these subjects, 131 were excluded due to inadequate follow-up data and 234 due to a history of VTE before the diagnosis of IBD. The remaining 45,037 IBD patients $(13,850$ $\mathrm{CD}$ and 31,187 UC patients) were included in the study. To create age- and sex-matched non-IBD controls, 133,019 subjects (41,073 CD and 91,946 UC) were randomly selected from the general population enrolled in the NHIS (Fig. 1). Detailed demographic characteristics of the study population are summarized in Table 1.

Table 2 shows the number of cases and the IRs of VTE in the IBD and non-IBD cohorts. During the follow-up period, VTE was diagnosed in 411 of 45,037 subjects in the IBD cohort $(0.9 \%)$ and 641 of 133,019 subjects in the nonIBD cohort (0.5\%). Among the VTE cases from the IBD cohort, 106 patients had previously been diagnosed with CD and 305 with UC. The IRs for VTE were 18.0 in the IBD cohort and 9.4 in the non-IBD cohort (IRR, 1.92; 95\% CI, 1.69 to 2.18). Subjects younger than 40 years of age were associated with the greatest IRR (age 0-19: IRR, 2.64; 95\% CI, 1.45 to 4.79 and age 20-39: IRR, 2.80; 95\% CI, 2.15 to 3.64). When subjects were stratified by type of IBD, the IRs for VTE were 16.1 in the $\mathrm{CD}$ group and 6.6 in the $\mathrm{CD}$ control group (IRR, 2.45; 95\% CI, 1.89 to 3.18). The IRs for the UC group and UC control group were 19.0 and 10.5,

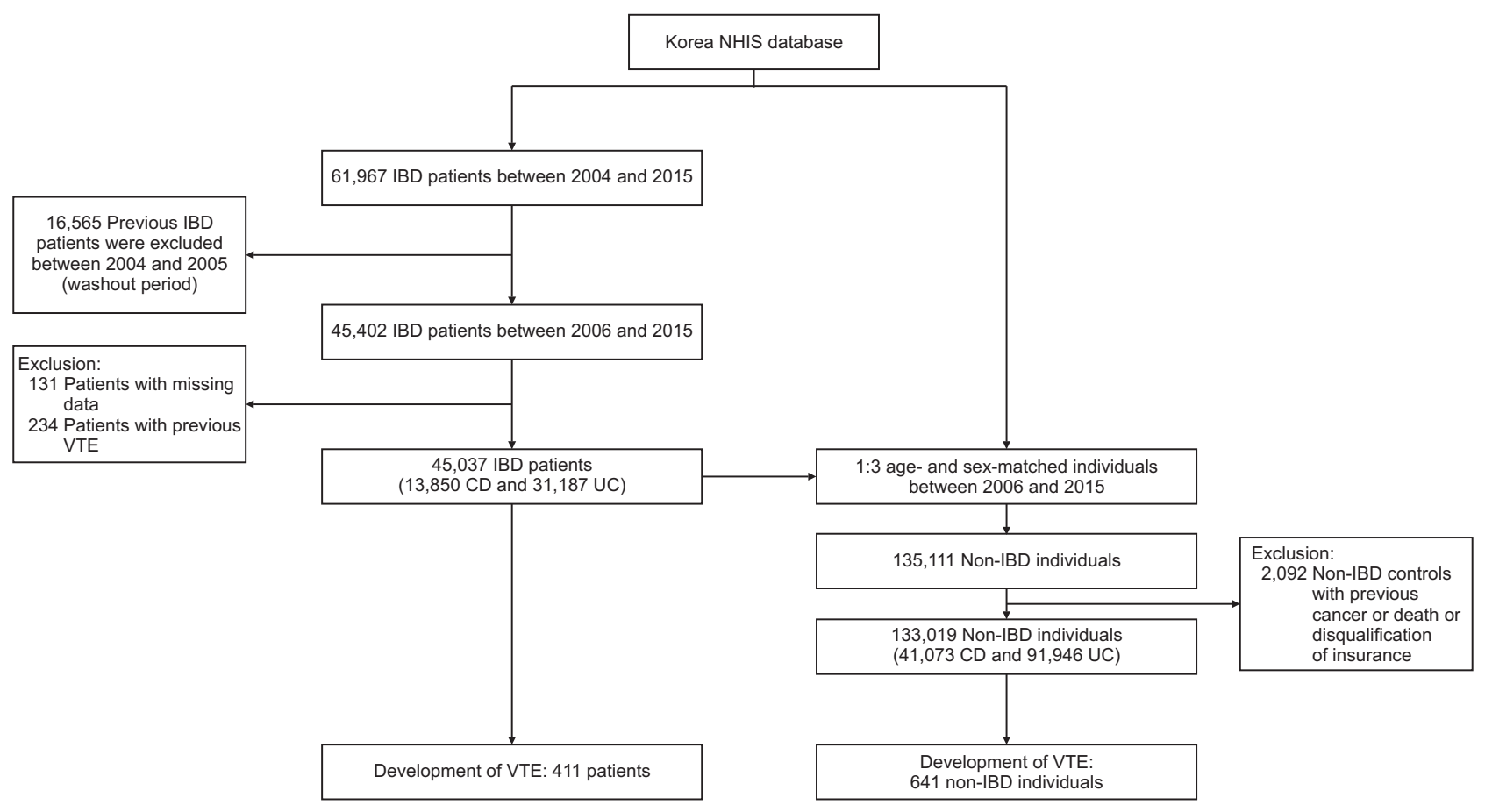

Fig. 1. Flowchart of this study.

NHIS, National Health Insurance System; IBD, inflammatory bowel disease; CD, Crohn's disease; UC, ulcerative colitis; VTE, venous thromboembolism. 
Table 1. Demographic Data of the IBD Cohort and the Matched Non-IBD Cohort between 2006 and 2015

\begin{tabular}{|c|c|c|c|c|}
\hline Variable & $\begin{array}{l}\text { IBD cohort } \\
\text { ( } n=45,037)\end{array}$ & $\begin{array}{c}C D \\
\text { (n=13,850) }\end{array}$ & $\begin{array}{c}\text { UC } \\
\text { (n=31,187) }\end{array}$ & $\begin{array}{l}\text { Non-IBD cohort } \\
\quad(n=133,019]\end{array}$ \\
\hline \multicolumn{5}{|l|}{ Age, yr } \\
\hline 0-19 & $6,251(13.9)$ & $4,230(30.5)$ & 2,021 (6.5) & $18,743(14.1)$ \\
\hline $20-39$ & $18,199(40.4)$ & $6,503(47.0)$ & 11,696 (37.5) & $53,988(40.6)$ \\
\hline $40-59$ & 14,429 (32.0) & $2,312(16.7)$ & 12,117 (38.9) & $42,696(32.1)$ \\
\hline$\geq 60$ & 6,158 (13.7) & 805 (5.8) & $5,353(17.1)$ & $17,592(13.2)$ \\
\hline \multicolumn{5}{|l|}{ Sex } \\
\hline Male & 28,046 (62.3) & $9,807(70.8)$ & $18,239(58.5)$ & $82,629(62.1)$ \\
\hline Female & 16,991 (37.7) & $4,043(29.2)$ & 12,948 (41.5) & 50,390 (37.9) \\
\hline \multicolumn{5}{|l|}{ Residence } \\
\hline Urban & 41,633 (92.4) & 12,955 (93.5) & $28,678(92.0)$ & $119,317(89.7)$ \\
\hline Rural & $3,404(7.6)$ & $895(6.5)$ & 2,509 (8.0) & 13,702 (10.3) \\
\hline \multicolumn{5}{|l|}{ Socioeconomic status* } \\
\hline Quintile 1 & 10,652 (23.7) & $3,299(23.8)$ & $7,353(23.6)$ & 33,731 (25.4) \\
\hline Quintile 2 & $13,241(29.4)$ & $4,152(30.0)$ & 9,089 (29.1) & $48,029(36.1)$ \\
\hline Quintile 3 & $21,144(46.9)$ & $6,399(46.2)$ & $14,745(47.3)$ & 51,259 (38.5) \\
\hline \multicolumn{5}{|l|}{$\mathrm{CCl}$ score } \\
\hline 0 & $13,767(30.6)$ & $5,065(36.6)$ & $8,702(27.9)$ & 50,371 (37.8) \\
\hline 1 & 14,708 (32.6) & $4,859(35.1)$ & $9,849(31.6)$ & 42,301 (31.8) \\
\hline 2 & $8,098(18.0)$ & $2,151(15.5)$ & $5,947(19.1)$ & $20,166(15.2)$ \\
\hline$\geq 3$ & $8,464(18.8)$ & $1,775(12.8)$ & $6,689(21.4)$ & $20,181(15.2)$ \\
\hline \multicolumn{5}{|l|}{ Comorbidities } \\
\hline Hypertension & 10,820 (24.0) & $1,860(13.4)$ & $8,960(28.7)$ & 31,578 (23.7) \\
\hline Diabetes mellitus & 10,513 (23.3) & $2,411(17.4)$ & $8,102(26.0)$ & 25,736 (19.3) \\
\hline Cardiovascular disease & $634(1.4)$ & $108(0.8)$ & $526(1.7)$ & $1,188(0.9)$ \\
\hline Atrial fibrillation & $513(1.1)$ & $117(0.8)$ & $396(1.3)$ & $1,038(0.8)$ \\
\hline Heart failure & $110(0.2)$ & $19(0.1)$ & $91(0.3)$ & $169(0.1)$ \\
\hline Cerebrovascular disease & $619(1.4)$ & 103 (0.7) & $516(1.7)$ & $1,244(0.9)$ \\
\hline Chronic kidney disease & 72 (0.2) & $21(0.2)$ & 51 (0.2) & $53(<0.1)$ \\
\hline Cancer & $1,946(4.3)$ & $369(2.7)$ & $1,577(5.1)$ & $4,828(3.6)$ \\
\hline \multicolumn{5}{|l|}{ Medications } \\
\hline Steroids & 21,757 (48.3) & $7,290(52.6)$ & $14,467(46.4)$ & $7,760(5.8)$ \\
\hline 5-ASA & 44,340 (98.5) & 13,418 (96.9) & 30,922 (99.2) & $26(<0.1)$ \\
\hline Thiopurines & $14,866(33.0)$ & $9,230(66.6)$ & $5,636(18.1)$ & $883(0.7)$ \\
\hline Anti-TNF-a agents & $5,019(11.1)$ & $3,438(24.8)$ & $1,581(5.1)$ & $32(<0.1)$ \\
\hline Aspirin & $6,970(15.5)$ & $1,429(10.3)$ & $5,541(17.8)$ & $19,626(14.8)$ \\
\hline Clopidogrel & $2,118(4.7)$ & $354(2.6)$ & $1,764(5.7)$ & $5,656(4.3)$ \\
\hline Warfarin & $377(0.8)$ & $83(0.6)$ & 294 (0.9) & $757(0.6)$ \\
\hline NOAC & $150(0.3)$ & $25(0.2)$ & $125(0.4)$ & 435 (0.3) \\
\hline Abdominal surgery history & 7,354 (16.3) & $5,760(41.6)$ & $1,594(5.1)$ & $2,340(1.8)$ \\
\hline Hospitalization & $34,869(77.4)$ & $12,450(89.9)$ & 22,419 (71.9) & $67,598(50.8)$ \\
\hline Follow-up period, yr & $5.03 \pm 2.94$ & $4.75 \pm 2.88$ & $5.16 \pm 2.95$ & $5.13 \pm 2.94$ \\
\hline
\end{tabular}

Data are presented as the number (\%) or mean \pm SD.

IBD, inflammatory bowel disease; CD, Crohn's disease; UC, ulcerative colitis; CCl, Charlson comorbidity index; 5-ASA, 5-aminosalicylic acid; TNF, tumor necrosis factor; NOAC, new oral anticoagulant.

*Socioeconomic status was calculated based on health insurance premium (from quintile 1 [low] to quintile 3 [high]).

respectively (IRR, $1.80 ; 95 \% \mathrm{CI}, 1.56$ to 2.08 ).

The risk of VTE was higher in the IBD cohort than in the non-IBD cohort (HR [crude], 1.93; 95\% CI, 1.71 to 2.19; $\mathrm{p}<0.001$; adjusted HR [model 1], 1.84; 95\% CI, 1.62 to $2.08 ; \mathrm{p}<0.001$; adjusted HR [model 2], $1.89 ; 95 \% \mathrm{CI}, 1.66$ to 2.14; $\mathrm{p}<0.001$ ) (Table 3). Compared to the non-IBD cohort, the HR associated with VTE in IBD patients tended to increase with a younger age or lower CCI score. The HR associated with VTE was especially high in young UC patients (age 0-19 years). We also stratified IRs and HRs by age at diagnosis of IBD (Fig. 2). Table 4 shows the mul- tivariate analysis of the risk factors associated with VTE in the IBD cohort. Age remained associated with an increased risk for VTE in IBD patients; particularly, patients aged $>59$ years had a higher adjusted HR of 4.10 (CD: 9.00, 95\% CI, 3.54 to $22.88 ; \mathrm{p}<0.001$ and UC: $2.26,95 \% \mathrm{CI}, 1.17$ to 4.34; $\mathrm{p}=0.015)$. In addition, female sex, an increased CCI score, the presence of cardiovascular or chronic kidney disease, use of steroids, and hospitalization were significant risk factors for VTE in patients with IBD. 
Kim SY, et al: Venous Thromboembolism in Asian IBD Patients

Table 2. Number of Incident Cases and Incidence Rates per 10,000 Person-Years of Venous Thromboembolism in the IBD and Non-IBD Cohorts

\begin{tabular}{|c|c|c|c|c|c|}
\hline \multirow{2}{*}{ Variable } & \multicolumn{2}{|c|}{ IBD cohort $(n=45,037)$} & \multicolumn{2}{|c|}{ Non-IBD cohort ( $n=133,019)$} & \multirow{2}{*}{ IRR $(95 \% \mathrm{CI})$} \\
\hline & Incident cases & Incidence rates & Incident cases & Incidence rates & \\
\hline Overall & 411 & 18.0 & 641 & 9.4 & $1.92(1.69-2.18)$ \\
\hline \multicolumn{6}{|l|}{ Age, yr } \\
\hline 0-19 & 21 & 7.5 & 24 & 2.8 & $2.64(1.45-4.79)$ \\
\hline $20-39$ & 111 & 11.9 & 119 & 4.3 & $2.80(2.15-3.64)$ \\
\hline $40-59$ & 140 & 18.6 & 244 & 10.8 & $1.73(1.40-2.13)$ \\
\hline$\geq 60$ & 139 & 46.4 & 254 & 27.5 & 1.69 (1.37-2.08) \\
\hline \multicolumn{6}{|l|}{ Sex } \\
\hline Male & 209 & 15.1 & 356 & 8.5 & $1.76(1.48-2.10)$ \\
\hline Female & 202 & 23.0 & 285 & 10.7 & 2.15 (1.79-2.58) \\
\hline \multicolumn{6}{|l|}{ Residence } \\
\hline Urban & 373 & 17.8 & 536 & 8.9 & $2.00(1.75-2.29)$ \\
\hline Rural & 38 & 21.8 & 103 & 14.3 & $1.52(1.04-2.22)$ \\
\hline \multicolumn{6}{|c|}{ Socioeconomic status } \\
\hline Quintile 1 & 117 & 22.2 & 195 & 11.2 & $1.99(1.57-2.51)$ \\
\hline Quintile 2 & 112 & 16.9 & 227 & 9.3 & 1.81 (1.44-2.28) \\
\hline Quintile 3 & 182 & 16.9 & 219 & 8.3 & $2.05(1.68-2.50)$ \\
\hline \multicolumn{6}{|l|}{$\mathrm{CCl}$ score } \\
\hline 0 & 59 & 9.0 & 78 & 3.2 & 2.83 (2.00-3.99) \\
\hline 1 & 98 & 13.5 & 148 & 6.9 & $1.95(1.50-2.53)$ \\
\hline 2 & 88 & 20.9 & 126 & 11.5 & $1.83(1.38-2.41)$ \\
\hline \multirow[t]{3}{*}{$\geq 3$} & 166 & 35.8 & 289 & 25.3 & $1.42(1.17-1.72)$ \\
\hline & \multicolumn{2}{|c|}{ Crohn's disease $(n=13,850)$} & \multicolumn{2}{|c|}{ Control group $(n=41,073)$} & \multirow{2}{*}{$\operatorname{IRR}(95 \% \mathrm{CI})$} \\
\hline & Incident cases & Incidence rates & Incident cases & Incidence rates & \\
\hline Overall & 106 & 16.1 & 131 & 6.6 & $2.45(1.89-3.18)$ \\
\hline \multicolumn{6}{|l|}{ Age, yr } \\
\hline $0-19$ & 9 & 4.9 & 19 & 3.4 & $1.43(0.63-3.20)$ \\
\hline $20-39$ & 38 & 11.9 & 42 & 4.4 & $2.72(1.74-4.26)$ \\
\hline $40-59$ & 35 & 30.0 & 36 & 10.1 & $2.98(1.86-4.79)$ \\
\hline$\geq 60$ & 24 & 65.3 & 34 & 29.5 & $2.21(1.30-3.77)$ \\
\hline \multicolumn{6}{|l|}{ Sex } \\
\hline Male & 60 & 13.0 & 80 & 5.7 & $2.26(1.61-3.19)$ \\
\hline Female & 46 & 23.5 & 51 & 8.6 & $2.74(1.83-4.12)$ \\
\hline \multicolumn{6}{|l|}{ Residence } \\
\hline Urban & 98 & 15.9 & 108 & 6.2 & $2.56(1.94-3.39)$ \\
\hline Rural & 8 & 18.7 & 21 & 10.4 & $1.80(0.78-4.13)$ \\
\hline \multicolumn{6}{|c|}{ Socioeconomic status } \\
\hline Quintile 1 & 30 & 19.7 & 44 & 8.3 & $2.37(1.47-3.80)$ \\
\hline Quintile 2 & 38 & 19.0 & 50 & 7.0 & $2.73(1.78-4.20)$ \\
\hline Quintile 3 & 38 & 12.4 & 37 & 5.0 & $2.50(1.57-3.96)$ \\
\hline \multicolumn{6}{|l|}{$\mathrm{CCl}$ score } \\
\hline 0 & 18 & 7.6 & 32 & 3.5 & $2.17(1.21-3.92)$ \\
\hline 1 & 28 & 12.5 & 34 & 5.3 & $2.34(1.41-3.90)$ \\
\hline 2 & 24 & 22.9 & 22 & 8.8 & $2.61(1.45-4.71)$ \\
\hline$\geq 3$ & 36 & 38.8 & 43 & 22.7 & 1.71 (1.09-2.68) \\
\hline
\end{tabular}

\section{DISCUSSION}

In this population-based nationwide study, we demonstrated that IBD patients exhibited a higher IRR (1.92; 95\% CI, 1.69 to 2.18 ) and a 1.93-fold greater risk (HR, 1.93; 95\% CI, 1.71 to 2.19 ; $\mathrm{p}<0.001$ ) of developing deep vein thrombosis than did the general population. HRs were especially high in the young IBD cohort compared to the non-IBD cohort, though the absolute risks increased with age. In particular, this trend was more pronounced in patients with UC than in those with $\mathrm{CD}$. We also showed that IBD is a powerful independent risk factor of VTE, because after adjusting for common VTE risk factors (diabetes mellitus, cardiovascular disease, atrial fibrillation, cerebral vascular disease, chronic kidney disease, and malignancy), patients with IBD had an approximately $90 \%$ higher risk of developing VTE than did controls. Another key finding in this study was the significant effect of IBD patient age on VTE occurrence. In IBD patients aged 60 years or older, the adjusted HR associated with VTE was much higher than that 


\begin{tabular}{|c|c|c|c|c|c|}
\hline & \multicolumn{2}{|c|}{ Ulcerative colitis ( $n=31,187)$} & \multicolumn{2}{|c|}{ Control group $(n=91,946)$} & \multirow{2}{*}{ IRR (95\% CI) } \\
\hline & Incident cases & Incidence rates & Incident cases & Incidence rates & \\
\hline Overall & 305 & 19.0 & 510 & 10.5 & $1.80(1.56-2.08)$ \\
\hline \multicolumn{6}{|l|}{ Age, yr } \\
\hline $0-19$ & 12 & 12.5 & 5 & 1.7 & $7.25(2.50-21.02)$ \\
\hline $20-39$ & 73 & 11.9 & 77 & 4.2 & $2.84(2.05-3.93)$ \\
\hline $40-59$ & 105 & 16.5 & 208 & 10.9 & $1.51(1.19-1.92)$ \\
\hline$\geq 60$ & 115 & 43.7 & 220 & 27.2 & $1.61(1.28-2.02)$ \\
\hline \multicolumn{6}{|l|}{ Sex } \\
\hline Male & 149 & 16.1 & 276 & 10.0 & $1.62(1.32-1.98)$ \\
\hline Female & 156 & 22.9 & 234 & 11.3 & $2.02(1.64-2.48)$ \\
\hline \multicolumn{6}{|l|}{ Residence } \\
\hline Urban & 275 & 18.6 & 428 & 10.0 & $1.86(1.59-2.17)$ \\
\hline Rural & 30 & 22.8 & 82 & 15.9 & $1.44(0.94-2.20)$ \\
\hline \multicolumn{6}{|c|}{ Socioeconomic status } \\
\hline Quintile 1 & 87 & 23.3 & 151 & 12.4 & $1.87(1.43-2.45)$ \\
\hline Quintile 2 & 74 & 16.0 & 177 & 10.3 & $1.55(1.17-2.04)$ \\
\hline Quintile 3 & 144 & 18.7 & 182 & 9.5 & $1.96(1.57-2.45)$ \\
\hline \multicolumn{6}{|l|}{$\mathrm{CCl}$ score } \\
\hline 0 & 41 & 9.8 & 46 & 3.0 & $3.26(2.12-5.01)$ \\
\hline 1 & 70 & 14.0 & 114 & 7.6 & $1.83(1.35-2.49)$ \\
\hline 2 & 64 & 20.3 & 104 & 12.2 & $1.66(1.21-2.28)$ \\
\hline$\geq 3$ & 130 & 35.0 & 246 & 25.8 & $1.36(1.09-1.69)$ \\
\hline
\end{tabular}

IBD, inflammatory bowel disease; IRR, incidence rate ratio; $\mathrm{Cl}$, confidence interval; $\mathrm{CCl}$, Charlson comorbidity index.

associated with people 19 years of age or younger.

Compared with previous studies on the occurrence of VTE in IBD patients, this study has the following strengths. First, this is the second nationwide study to evaluate the risk of deep vein thrombosis among IBD patients in an Asian population, with a different result from the first study. ${ }^{17}$ This study targeted four times more IBD patients than did the previous study, and the follow-up duration was longer. Therefore, the reliability and accuracy of the results of this study are expected to be higher. Second, although past studies have focused on the occurrence of VTE in specific situations and derived their results accordingly, ${ }^{9,15,16,18,19}$ this study examines the general occurrence of VTE in the wider population. Therefore, the association between IBD and VTE could be evaluated at the level of the entire population. Third, this study selected newly diagnosed IBD patients as an inception cohort. Whereas the ability to determine a clear relationship between early exposure factors and long-term outcomes is limited in a non-inception cohort, the inception cohort was free from these disadvantages and provided additional enhancement in data quality. ${ }^{33}$ The fourth strength of this study is that it included a large number of subjects by using data from the NHIS. Research using the NHIS database is advantageous in that it is easy to derive research results for a large number of people at the national level, thus providing realworld evidence with relatively little effort and time.

In general, IBD was associated with an increased risk of VTE, and our findings concur with those of previous population-based cohort studies. ${ }^{3,4,34}$ A previous Western study, however, found that the risk of VTE was 2- to 3-fold higher or even greater in an IBD population compared to the control. In the present study, we found a relatively lower HR increase (1.93) compared to the non-IBD cohort. Similar to our results, in a Taiwanese population-based study, the adjusted HR increased relatively slightly to $1.98 .{ }^{17}$ The differences in VTE risk for IBD patients in Asia and Western countries may be associated with racial differences and dietary habits. ${ }^{35,36}$ However, it is clear that IBD patients face an increased risk of VTE regardless of ethnicity or region. Therefore, there is some consensus that thromboprophylaxis should be considered for IBD patients who are indicated for prophylaxis. ${ }^{12,13}$ Nevertheless, some studies have shown that there is still a large gap in the use of VTE prophylaxis by gastroenterologists in clinical practice. ${ }^{24,37}$ There are several reasons for low compliance in terms of thromboprophylaxis by doctors. First, they may have concerns about the safety of thromboprophylaxis when active IBD patients are hospitalized; ${ }^{38,39}$ however, previous studies have reported that pharmacological thromboprophylaxis of VTE does not increase the risk of bleeding. ${ }^{38,40}$ Second, gastroenterologists may not be aware of the increased risk of VTE in IBD patients, and thus do not follow the guidelines recommending prophylactic anticoagulant therapy in hospitalized IBD patients. ${ }^{37}$ The failure to adhere to these guidelines is more prevalent in Asia. ${ }^{24}$ The consequences of 
Table 3. Comparison of the Risk of Venous Thromboembolic Events between the IBD and Non-IBD Cohorts

\begin{tabular}{|c|c|c|c|c|c|c|}
\hline \multirow{2}{*}{ Variable } & \multicolumn{2}{|c|}{ Crude } & \multicolumn{2}{|c|}{ Model $1 *$} & \multicolumn{2}{|c|}{ Model $2^{+}$} \\
\hline & $\mathrm{HR}(95 \% \mathrm{Cl})$ & p-value & Adjusted HR (95\% CI) & p-value & Adjusted HR (95\% CI) & $p$-value \\
\hline \multicolumn{7}{|l|}{ IBD vs non-IBD } \\
\hline Non-IBD & Reference & & Reference & & Reference & \\
\hline IBD & $1.93(1.71-2.19)$ & $<0.001$ & 1.84 (1.62-2.08) & $<0.001$ & $1.89(1.66-2.14)$ & $<0.001$ \\
\hline \multicolumn{7}{|l|}{ Age, yr } \\
\hline 0-19 & $2.64(1.47-4.74)$ & 0.001 & $2.43(1.33-4.43)$ & 0.004 & $2.61(1.41-4.83)$ & 0.002 \\
\hline $20-39$ & $2.79(2.16-3.62)$ & $<0.001$ & $2.63(2.02-3.42)$ & $<0.001$ & $2.73(2.10-3.56)$ & $<0.001$ \\
\hline $40-59$ & $1.73(1.40-2.13)$ & $<0.001$ & $1.64(1.33-2.02)$ & $<0.001$ & $1.66(1.35-2.05)$ & $<0.001$ \\
\hline$\geq 60$ & $1.68(1.37-2.07)$ & $<0.001$ & $1.62(1.31-1.99)$ & $<0.001$ & $1.62(1.32-2.00)$ & $<0.001$ \\
\hline \multicolumn{7}{|l|}{ Sex } \\
\hline Male & $1.76(1.48-2.09)$ & $<0.001$ & $1.66(1.40-1.98)$ & $<0.001$ & 1.70 (1.42-2.02) & $<0.001$ \\
\hline Female & $2.15(1.80-2.57)$ & $<0.001$ & 2.08 (1.74-2.49) & $<0.001$ & 2.12 (1.77-2.55) & $<0.001$ \\
\hline \multicolumn{7}{|l|}{$\mathrm{CCl}$ score } \\
\hline 0 & $2.17(1.22-3.87)$ & 0.008 & $2.49(1.38-4.50)$ & 0.002 & $2.44(1.33-4.49)$ & 0.004 \\
\hline 1 & $2.34(1.42-3.86)$ & 0.001 & $2.57(1.55-4.28)$ & $<0.001$ & $2.66(1.59-4.44)$ & $<0.001$ \\
\hline 2 & $2.65(1.48-4.72)$ & 0.001 & $2.95(1.65-5.28)$ & $<0.001$ & $3.01(1.67-5.43)$ & $<0.001$ \\
\hline$\geq 3$ & $1.72(1.10-2.67)$ & 0.017 & $1.87(1.20-2.91)$ & 0.006 & $1.92(1.23-3.02)$ & 0.004 \\
\hline Hospitalization & $1.84(1.36-2.49)$ & $<0.001$ & $2.27(1.67-3.09)$ & $<0.001$ & $2.29(1.68-3.13)$ & $<0.001$ \\
\hline \multicolumn{7}{|l|}{ CD vs control } \\
\hline Control & Reference & & Reference & & Reference & \\
\hline$C D$ & $2.45(1.90-3.17)$ & $<0.001$ & 2.34 (1.80-3.03) & $<0.001$ & $2.43(1.87-3.16)$ & $<0.001$ \\
\hline \multicolumn{7}{|l|}{ Age, yr } \\
\hline 0-19 & $1.43(0.65-3.15)$ & 0.380 & $1.34(0.60-3.02)$ & 0.474 & $1.42(0.62-3.25)$ & 0.407 \\
\hline $20-39$ & $2.72(1.75-4.22)$ & $<0.001$ & $2.60(1.66-4.08)$ & $<0.001$ & $2.81(1.78-4.42)$ & $<0.001$ \\
\hline $40-59$ & $2.98(1.87-4.75)$ & $<0.001$ & $2.87(1.79-4.59)$ & $<0.001$ & 2.85 (1.77-4.58) & $<0.001$ \\
\hline$\geq 60$ & $2.24(1.33-3.78)$ & 0.003 & $2.12(1.24-3.62)$ & 0.006 & $2.29(1.33-3.94)$ & 0.003 \\
\hline \multicolumn{7}{|l|}{ Sex } \\
\hline Male & $2.27(1.62-3.17)$ & $<0.001$ & $2.15(1.53-3.03)$ & $<0.001$ & $2.22(1.57-3.13)$ & $<0.001$ \\
\hline Female & $2.75(1.84-4.09)$ & $<0.001$ & $2.70(1.80-4.04)$ & $<0.001$ & 2.74 (1.82-4.13) & $<0.001$ \\
\hline \multicolumn{7}{|l|}{ CCl score } \\
\hline 0 & $2.17(1.22-3.87)$ & 0.008 & $2.49(1.38-4.50)$ & 0.002 & $2.44(1.33-4.49)$ & 0.004 \\
\hline 1 & $2.34(1.42-3.86)$ & 0.001 & $2.57(1.55-4.28)$ & $<0.001$ & $2.66(1.59-4.44)$ & $<0.001$ \\
\hline 2 & 2.65 (1.48-4.72) & 0.001 & $2.95(1.65-5.28)$ & $<0.001$ & 3.01 (1.67-5.43) & $<0.001$ \\
\hline$\geq 3$ & $1.72(1.10-2.67)$ & 0.017 & $1.87(1.20-2.91)$ & 0.006 & $1.92(1.23-3.02)$ & 0.004 \\
\hline Hospitalization & $1.84(1.36-2.49)$ & $<0.001$ & $2.27(1.67-3.09)$ & $<0.001$ & 2.29 (1.68-3.13) & $<0.001$ \\
\hline \multicolumn{7}{|l|}{ UC vs control } \\
\hline Control & Reference & & Reference & & Reference & \\
\hline UC & $1.80(1.56-2.07)$ & $<0.001$ & $1.71(1.49-1.98)$ & $<0.001$ & 1.76 (1.52-2.03) & $<0.001$ \\
\hline \multicolumn{7}{|l|}{ Age, yr } \\
\hline $0-19$ & 7.25 (2.55-20.56) & $<0.001$ & $6.49(2.24-18.82)$ & 0.001 & $6.79(2.31-19.99)$ & 0.001 \\
\hline $20-39$ & $2.83(2.06-3.90)$ & $<0.001$ & $2.63(1.90-3.63)$ & $<0.001$ & $2.69(1.94-3.73)$ & $<0.001$ \\
\hline $40-59$ & $1.51(1.20-1.91)$ & 0.001 & $1.44(1.14-1.82)$ & 0.003 & $1.48(1.16-1.87)$ & 0.001 \\
\hline$\geq 60$ & $1.60(1.28-2.01)$ & $<0.001$ & $1.55(1.24-1.94)$ & $<0.001$ & $1.56(1.24-1.96)$ & $<0.001$ \\
\hline \multicolumn{7}{|l|}{ Sex } \\
\hline Male & $1.61(1.32-1.97)$ & $<0.001$ & $1.53(1.25-1.87)$ & $<0.001$ & 1.55 (1.27-1.90) & $<0.001$ \\
\hline Female & $2.02(1.65-2.47)$ & $<0.001$ & $1.96(1.60-2.40)$ & $<0.001$ & $2.00(1.63-2.45)$ & $<0.001$ \\
\hline \multicolumn{7}{|l|}{ CCl score } \\
\hline 0 & $3.25(2.13-4.95)$ & $<0.001$ & $3.21(2.10-4.90)$ & $<0.001$ & 3.29 (2.15-5.05) & $<0.001$ \\
\hline 1 & $1.83(1.36-2.47)$ & $<0.001$ & $1.93(1.43-2.60)$ & $<0.001$ & $2.03(1.51-2.75)$ & $<0.001$ \\
\hline 2 & $1.66(1.21-2.26)$ & 0.002 & $1.73(1.27-2.37)$ & 0.001 & 1.75 (1.28-2.39) & 0.001 \\
\hline$\geq 3$ & 1.35 (1.09-1.67) & 0.005 & $1.40(1.13-1.74)$ & 0.002 & 1.39 (1.12-1.72) & 0.003 \\
\hline Hospitalization & $1.79(1.52-2.12)$ & $<0.001$ & $1.92(1.62-2.27)$ & $<0.001$ & $1.94(1.64-2.30)$ & $<0.001$ \\
\hline
\end{tabular}

$\mathrm{IBD}$, inflammatory bowel disease; $\mathrm{HR}$, hazard ratio; $\mathrm{Cl}$, confidence interval; $\mathrm{CCl}$, Charlson comorbidity index; CD, Crohn's disease; UC, ulcerative colitis.

*Multivariable-adjusted model 1: adjustments for age, sex, $\mathrm{CCl}$ score, socioeconomic status, and residence; ${ }^{\dagger}$ Multivariable-adjusted model 2: adjustments for model 1 covariates and comorbidities. 


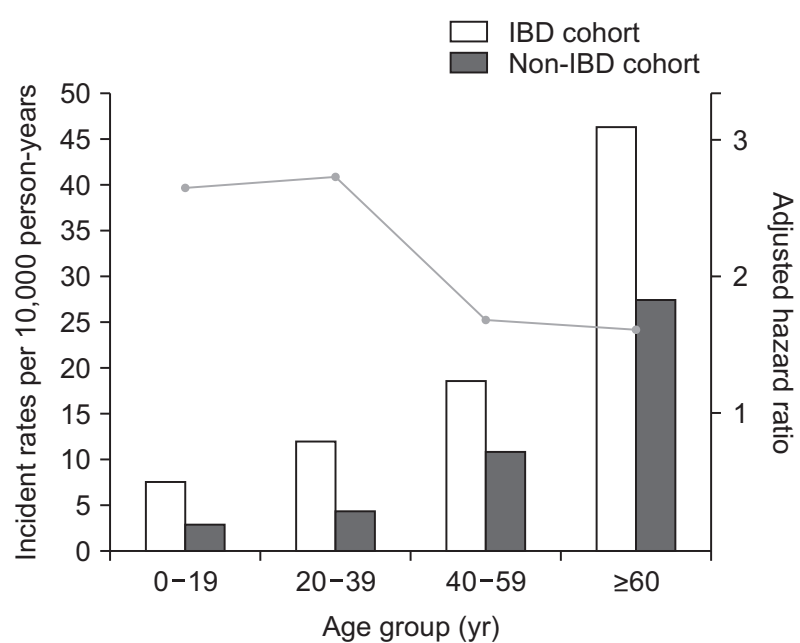

Fig. 2. Incidence rates and adjusted hazard ratios (model 2) of venous thromboembolism in patients with inflammatory bowel disease (IBD) compared with non-IBD controls by age group.

VTE can be fatal, and its incidence is clearly higher in IBD patients than in the general population, so correct VTE prophylaxis must be performed based on the guidelines.

This study revealed several interesting findings regarding the development of VTE according to age in IBD patients. The IRR and HR associated with VTE in patients with IBD versus the non-IBD cohort was approximately two to three times higher in the younger age group $(<40$ years) than in the elderly. In particular, this trend was more apparent in those with UC than in those with CD. Previous studies have also demonstrated that younger IBD patients (including children and adolescents) had a higher risk of developing VTE compared to age-matched non-IBD controls. ${ }^{4,19,41}$ Considering these results alone, the VTE risk of young IBD patients appears to be very high, but in fact, among all IBD patients, the absolute incidence of VTE is very low at a young age versus an older age. In fact, the IR for VTE in elderly IBD patients (aged 60 years or older) was 46.4, whereas the IRs for ages 0-19 and 20-39 were only 7.5 and 11.9 , respectively. Moreover, elderly patients had increased risk for VTE in the IBD cohort. Therefore, since VTE hardly occurred in young subjects belonging to the non-IBD cohort, it is thought that the IRR and HR of the VTE were noticeable higher in the young IBD patients compared with the non-IBD cohort. The current guidelines do not recommend thromboprophylaxis for young IBD patients (younger than 18 years of age) who have no previous history of VTE. ${ }^{12}$

The other important point we found was the different pattern of VTE development in CD and UC. The incidence of VTE according to age was generally similar between patients with $\mathrm{CD}$ and UC. However, the age-related risk of VTE was more pronounced in CD cases (the adjusted
HR for CD patients over 60 years of age was 9.00) than in UC cases (the adjusted HR for patients over 60 years of age was 2.26). The reason for this phenomenon is not clear, but it may have to do with two characteristics of Korean UC patients as seen in a recent epidemiology study. ${ }^{20}$ The first is that the number of elderly UC patients has increased significantly, and the other is that the proportion of patients with proctitis is high. Considering the higher risk of VTE in cases with widespread bowel involvement (e.g., pancolitis), ${ }^{3,4,10}$ we can speculate that the increase in the number of elderly patients with mild UC may be the major reason for this phenomenon.

VTE in IBD patients is a multifactorial event caused not only by inherited risk but also by acquired factors. ${ }^{40,42-44}$ Several risk factors are more common in IBD patients than in the general population, including hyperhomocysteinemia, dehydration, infection, prolonged immobilization, and active intestinal disease. ${ }^{40,42,45}$ In addition, the risk of VTE in IBD patients may increase when it is accompanied by other diseases known to be risk factors for VTE. This hypothesis is supported by the fact that the HR value for VTE gradually increased with CCI score in this study. Of note, chronic kidney disease was associated with a significant risk of VTE (adjusted HR, 3.36; 95\% CI, 1.24 to 9.14; $\mathrm{p}=0.018$ ). This is the first report indicating that chronic kidney disease may be a risk factor for VTE in IBD patients, although one small study previously reported an increased use of VTE prophylaxis in IBD patients with chronic kidney disease. ${ }^{46}$ Also, patients with chronic kidney disease have a higher risk of developing VTE than those with normal kidney function in the nonIBD group. ${ }^{47}$ Therefore, if chronic kidney disease is present in IBD patients, it is important to keep in mind that the likelihood of developing VTE will be high, and proactive prophylaxis should be considered.

Due to the nature of IBD, most patients have to take lifelong medication to control the disease. However, little research has been done on whether these medications increase the risk of VTE. We found that prior use of steroids increases the risk of VTE (adjusted HR, 1.88; 95\% CI, 1.51 to $2.33 ; \mathrm{p}<0.001$ ), similar to previous studies. ${ }^{48,49}$ According to a recent meta-analysis, steroid usage was associated with a significantly higher rate of VTE complication in IBD patients (odds ratio, 2.202; 95\% CI, 1.698 to 2.856 ; $\mathrm{p}<0.001$ ). ${ }^{48}$ Corticosteroids may elevate thrombogenic risks via mechanisms associated with inflammatory processes, such as excessive production of procoagulant factors and impaired fibrinolytic capacity. ${ }^{11,50}$ Therefore, caution is particularly needed when using steroids in elderly IBD patients because of the potential high risk of VTE. ${ }^{51}$

Although our results can be generalized in Korea be- 
Table 4. Multivariate Analysis of Risk Factors for Venous Thromboembolism in an the IBD Cohort

\begin{tabular}{|c|c|c|c|c|c|c|}
\hline \multirow{2}{*}{ Factor } & \multicolumn{2}{|l|}{ IBD } & \multicolumn{2}{|l|}{$C D$} & \multicolumn{2}{|l|}{ UC } \\
\hline & Adjusted HR (95\% CI) & $\mathrm{p}$-value & Adjusted HR (95\% Cl) & p-value & Adjusted HR (95\% CI) & $\mathrm{p}$-value \\
\hline \multicolumn{7}{|l|}{ Disease type } \\
\hline $\mathrm{CD}$ & Reference & & & & & \\
\hline UC & $0.77(0.60-0.99)$ & 0.043 & & & & \\
\hline \multicolumn{7}{|l|}{ Age, yr } \\
\hline $0-19$ & Reference & & Reference & & Reference & \\
\hline $20-39$ & $1.64(1.01-2.64)$ & 0.044 & $2.16(1.03-4.51)$ & 0.042 & 1.04 (0.56-1.93) & 0.895 \\
\hline $40-59$ & $2.25(1.36-3.70)$ & 0.002 & $4.63(2.06-10.40)$ & $<0.001$ & $1.22(0.66-2.27)$ & 0.527 \\
\hline$\geq 60$ & $4.10(2.40-7.02)$ & $<0.001$ & 9.00 (3.54-22.88) & $<0.001$ & $2.26(1.17-4.34)$ & 0.015 \\
\hline \multicolumn{7}{|l|}{ Sex } \\
\hline Male & Reference & & Reference & & Reference & \\
\hline Female & $1.28(1.05-1.56)$ & 0.014 & $1.18(0.79-1.76)$ & 0.415 & $1.30(1.03-1.63)$ & 0.025 \\
\hline \multicolumn{7}{|l|}{ Residence } \\
\hline Urban & Reference & & Reference & & Reference & \\
\hline Rural & $0.92(0.65-1.28)$ & 0.608 & $0.87(0.42-1.81)$ & 0.708 & $0.92(0.63-1.35)$ & 0.662 \\
\hline \multicolumn{7}{|l|}{$\mathrm{CCl}$ score } \\
\hline 0 & Reference & & Reference & & Reference & \\
\hline 1 & 1.36 (0.98-1.88) & 0.065 & $1.41(0.78-2.55)$ & 0.259 & 1.34 (0.91-1.97) & 0.143 \\
\hline 2 & $1.84(1.30-2.59]$ & 0.001 & $1.84(0.97-3.50)$ & 0.100 & $1.80(1.20-2.71)$ & 0.005 \\
\hline$\geq 3$ & $2.34(1.64-3.35)$ & $<0.001$ & $2.05(1.02-4.12)$ & $<0.001$ & $2.39(1.57-3.64)$ & $<0.001$ \\
\hline \multicolumn{7}{|l|}{ Comorbidities } \\
\hline Hypertension & $1.23(0.96-1.59)$ & 0.105 & $0.87(0.51-1.48)$ & 0.598 & 1.37 (1.03-1.83) & 0.034 \\
\hline Diabetes mellitus & $0.82(0.65-1.04)$ & 0.107 & $0.80(0.49-1.31)$ & 0.385 & $0.82(0.62-1.08)$ & 0.157 \\
\hline CAOD & $1.81(1.14-2.85)$ & 0.011 & $0.46(0.06-3.38)$ & 0.444 & $2.14(1.34-3.44)$ & 0.002 \\
\hline Atrial fibrillation & $1.54(0.90-2.64)$ & 0.117 & $0.89(0.20-3.93)$ & 0.879 & $1.76(0.99-3.14)$ & 0.054 \\
\hline Heart failure & $0.30(0.04-2.12)$ & 0.225 & $0.01(0.01-0.03)$ & 0.983 & $0.31(0.04-2.24)$ & 0.246 \\
\hline CVD & $0.79(0.45-1.41)$ & 0.425 & $0.30(0.04-2.28)$ & 0.244 & $0.92(0.51-1.69)$ & 0.794 \\
\hline CKD & $3.36(1.24-9.14)$ & 0.018 & $4.36(0.55-34.53)$ & 0.163 & $3.38(1.06-10.72)$ & 0.039 \\
\hline Cancer & $1.11(0.78-1.58)$ & 0.564 & $1.42(0.69-2.92)$ & 0.336 & $1.05(0.70-1.57)$ & 0.832 \\
\hline \multicolumn{7}{|l|}{ IBD medications } \\
\hline Steroids & $1.88(1.51-2.33)$ & $<0.001$ & $2.09(1.36-3.21)$ & 0.001 & $1.79(1.39-2.30)$ & $<0.001$ \\
\hline $5-A S A$ & $0.15(0.09-0.25)$ & $<0.001$ & $0.15(0.07-0.31)$ & $<0.001$ & $0.15(0.08-0.30)$ & $<0.001$ \\
\hline Thiopurines & $0.53(0.39-0.71)$ & $<0.001$ & $0.47(0.29-0.77)$ & 0.002 & $0.59(0.41-0.85)$ & 0.004 \\
\hline Anti-TNF-a agents & $0.80(0.52-1.22)$ & 0.304 & $0.80(0.44-1.44)$ & 0.451 & $0.87(0.48-1.59)$ & 0.654 \\
\hline Abdominal surgery history & $0.94(0.68-1.31)$ & 0.720 & $1.01(0.64-1.58)$ & 0.980 & $0.97(0.59-1.57)$ & 0.887 \\
\hline Hospitalization & $1.56(1.22-1.98)$ & $<0.001$ & $1.39(0.85-2.27)$ & 0.187 & $1.60(1.21-2.12)$ & 0.001 \\
\hline
\end{tabular}

Adjustments were made for all variables listed in the table.

IBD, inflammatory bowel disease; CD, Crohn's disease; UC, ulcerative colitis; HR, hazard ratio; $\mathrm{Cl}$, confidence interval; $\mathrm{CCl}$, Charlson comorbidity index; CAOD, cardiovascular disease; CVD, cerebrovascular disease; CKD, chronic kidney disease; 5-ASA, 5-aminosalicylic acid; TNF, tumor necrosis factor.

cause of the use of the NHIS database, our study has several limitations mainly related to the features of the claims data, which is an innate limitation. First, we were not able to evaluate the disease severity (clinical or endoscopic) and disease extent of IBD, which may be linked to VTE development. Also, the severity of VTE (fatal VTE, VTE induced permanent damage, etc.) was not evaluated. Second, there was no information on possible confounding factors, such as smoking status, obesity, major trauma, oral contraceptive therapy, or pregnancy, which are essential variables that may modify VTE risk.

In conclusion, IBD is a definite independent risk factor for VTE at the population level. This study also showed that Asian IBD patients had a higher risk of VTE than did a non-IBD cohort. In addition, we found multiple risk fac- tors to be associated with the occurrence of VTE in IBD patients, including an older age, female sex, a high CCI score, cardiovascular disease, chronic kidney disease, use of steroids, and hospitalization. Based on these findings, a prospective study to clarify the indications of thromboprophylaxis and therapeutic outcomes based on patient characteristics is warranted.

\section{CONFLICTS OF INTEREST}

No potential conflict of interest relevant to this article was reported. 


\section{ACKNOWLEDGEMENTS}

This work was supported by grants from the National Research Foundation of Korea (2019R1A2C1007859), Ministry of Science and ICT, the National R\&D Program for Cancer Control (HA17C0046) and the Korean National Health Clinical Research (NHCR) project (HC16C2320), Ministry of Health \& Welfare, Republic of Korea. This research was supported by Basic Science Research Program through the National Research Foundation of Korea (NRF) funded by the Ministry of Education (grant number: 2020R1I1A306686511).

\section{AUTHOR CONTRIBUTIONS}

Concept and design: S.Y.K., Y.S.C., H.S.K. Acquisition and analysis of data: J.K.L., D.R.K. Interpretation of data: S.Y.K., Y.S.C., H.S.K., H.M.K., H.J.P., H.K., J.K. Statistical analysis: J.K.L., D.R.K. Obtained funding: S.Y.K., H.S.K. Administrative, technical, or material support: H.M.K., H.J.P., H.K., J.K. Supervision: S.Y.K., H.S.K. Drafting of the manuscript: S.Y.K., Y.S.C., J.K.L., D.R.K. Critical revision of the manuscript for important intellectual content: S.Y.K., Y.S.C., H.S.K.

\section{ORCID}

Su Young Kim

Yeon Seo Cho Hyun-Soo Kim

Jung Kuk Lee Hee Man Kim Hong Jun Park Hyunil Kim Jihoon Kim Dae Ryong Kang https://orcid.org/0000-0002-6486-8445 https://orcid.org/0000-0002-1039-0044 https://orcid.org/0000-0001-7190-0362 https://orcid.org/0000-0003-1874-449X https://orcid.org/0000-0002-7983-1928 https://orcid.org/0000-0001-9320-9978 https://orcid.org/0000-0002-0551-6650 https://orcid.org/0000-0001-9050-1172 https://orcid.org/0000-0002-8792-9730

\section{REFERENCES}

1. Mizoguchi E, Low D, Ezaki Y, Okada T. Recent updates on the basic mechanisms and pathogenesis of inflammatory bowel diseases in experimental animal models. Intest Res 2020;18:151-167.

2. Kim JM, Cheon JH. Pathogenesis and clinical perspectives of extraintestinal manifestations in inflammatory bowel diseases. Intest Res 2020;18:249-264.

3. Grainge MJ, West J, Card TR. Venous thromboembolism during active disease and remission in inflammatory bowel disease: a cohort study. Lancet 2010;375:657-663.

4. Kappelman MD, Horvath-Puho E, Sandler RS, et al. Thromboembolic risk among Danish children and adults with inflammatory bowel diseases: a population-based nationwide study. Gut 2011;60:937-943.

5. Murthy SK, Nguyen GC. Venous thromboembolism in inflammatory bowel disease: an epidemiological review. Am J Gastroenterol 2011;106:713-718.

6. Ng SC, Shi HY, Hamidi N, et al. Worldwide incidence and prevalence of inflammatory bowel disease in the 21 st century: a systematic review of population-based studies. Lancet 2017;390:2769-2778.

7. Coward S, Clement F, Benchimol EI, et al. Past and future burden of inflammatory bowel diseases based on modeling of population-based data. Gastroenterology 2019;156:13451353.

8. Yuhara H, Steinmaus C, Corley D, et al. Meta-analysis: the risk of venous thromboembolism in patients with inflammatory bowel disease. Aliment Pharmacol Ther 2013;37:953962.

9. Chu TP, Grainge MJ, Card TR. The risk of venous thromboembolism during and after hospitalisation in patients with inflammatory bowel disease activity. Aliment Pharmacol Ther 2018;48:1099-1108.

10. Miehsler W, Reinisch W, Valic E, et al. Is inflammatory bowel disease an independent and disease specific risk factor for thromboembolism? Gut 2004;53:542-548.

11. Cheng K, Faye AS. Venous thromboembolism in inflammatory bowel disease. World J Gastroenterol 2020;26:12311241.

12. Nguyen GC, Bernstein CN, Bitton A, et al. Consensus statements on the risk, prevention, and treatment of venous thromboembolism in inflammatory bowel disease: Canadian Association of Gastroenterology. Gastroenterology 2014;146:835-848.

13. Gionchetti P, Dignass A, Danese S, et al. 3rd European evidence-based consensus on the diagnosis and management of Crohn's disease 2016: part 2: surgical management and special situations. J Crohns Colitis 2017;11:135-149.

14. Bitton A, Buie D, Enns R, et al. Treatment of hospitalized adult patients with severe ulcerative colitis: Toronto consensus statements. Am J Gastroenterol 2012;107:179-194.

15. Faye AS, Wen T, Ananthakrishnan AN, et al. Acute venous thromboembolism risk highest within 60 days after discharge from the hospital in patients with inflammatory bowel diseases. Clin Gastroenterol Hepatol 2020;18:1133-1141.

16. Higgins PD, Skup M, Mulani PM, Lin J, Chao J. Increased risk of venous thromboembolic events with corticosteroid vs biologic therapy for inflammatory bowel disease. Clin Gastroenterol Hepatol 2015;13:316-321.

17. Chung WS, Lin CL, Hsu WH, Kao CH. Inflammatory bowel 
disease increases the risks of deep vein thrombosis and pulmonary embolism in the hospitalized patients: a nationwide cohort study. Thromb Res 2015;135:492-496.

18. McCurdy JD, Kuenzig ME, Smith G, et al. Risk of venous thromboembolism after hospital discharge in patients with inflammatory bowel disease: a population-based study. Inflamm Bowel Dis 2020;26:1761-1768.

19. McKie K, McLoughlin RJ, Hirsh MP, Cleary MA, Aidlen JT. Risk factors for venous thromboembolism in children and young adults with inflammatory bowel disease. J Surg Res 2019;243:173-179.

20. Park SH, Kim YJ, Rhee KH, et al. A 30-year trend analysis in the epidemiology of inflammatory bowel disease in the Songpa-Kangdong district of Seoul, Korea in 1986-2015. J Crohns Colitis 2019;13:1410-1417.

21. Cha JM, Park SH, Rhee KH, et al. Long-term prognosis of ulcerative colitis and its temporal changes between 1986 and 2015 in a population-based cohort in the Songpa-Kangdong district of Seoul, Korea. Gut 2020;69:1432-1440.

22. Chuang CH, Lin SH, Chen CY, Sheu BS, Kao AW, Wang JD. Increasing incidence and lifetime risk of inflammatory bowel disease in Taiwan: a nationwide study in a low-endemic area 1998-2010. Inflamm Bowel Dis 2013;19:2815-2819.

23. Ng SC, Tang W, Ching JY, et al. Incidence and phenotype of inflammatory bowel disease based on results from the Asiapacific Crohn's and colitis epidemiology study. Gastroenterology 2013;145:158-165.

24. Song HK, Lee KM, Jung SA, et al. Quality of care in inflammatory bowel disease in Asia: the results of a multinational web-based survey in the 2(nd) Asian Organization of Crohn's and Colitis (AOCC) meeting in Seoul. Intest Res 2016;14:240-247.

25. Cheuk BL, Cheung GC, Cheng SW. Epidemiology of venous thromboembolism in a Chinese population. Br J Surg 2004;91:424-428.

26. Oger E. Incidence of venous thromboembolism: a community-based study in Western France. EPI-GETBP Study Group. Groupe d'Etude de la Thrombose de Bretagne Occidentale. Thromb Haemost 2000;83:657-660.

27. Song SO, Jung $\mathrm{CH}$, Song YD, et al. Background and data configuration process of a nationwide population-based study using the Korean National Health Insurance System. Diabetes Metab J 2014;38:395-403.

28. Jung YS, Han M, Park S, Kim WH, Cheon JH. Cancer risk in the early stages of inflammatory bowel disease in Korean patients: a nationwide population-based study. J Crohns Colitis 2017;11:954-962.

29. Jung YS, Han M, Kim WH, Park S, Cheon JH. Incidence and clinical outcomes of inflammatory bowel disease in South Korea, 2011-2014: a nationwide population-based study. Dig Dis Sci 2017;62:2102-2112.
30. Lee CK, Ha HJ, Oh SJ, et al. Nationwide validation study of diagnostic algorithms for inflammatory bowel disease in Korean National Health Insurance Service database. J Gastroenterol Hepatol 2020;35:760-768.

31. Seong SC, Kim YY, Khang YH, et al. Data resource profile: the National Health Information Database of the National Health Insurance Service in South Korea. Int J Epidemiol 2017;46:799-800.

32. Lee J, Lee JS, Park SH, Shin SA, Kim K. Cohort profile: the National Health Insurance Service-National Sample Cohort (NHIS-NSC), South Korea. Int J Epidemiol 2017;46:e15.

33. Bernard TJ, Armstrong-Wells J, Goldenberg NA. The institution-based prospective inception cohort study: design, implementation, and quality assurance in pediatric thrombosis and stroke research. Semin Thromb Hemost 2013;39:10-14.

34. Bernstein CN, Blanchard JF, Houston DS, Wajda A. The incidence of deep venous thrombosis and pulmonary embolism among patients with inflammatory bowel disease: a population-based cohort study. Thromb Haemost 2001;85:430-434.

35. Stein PD, Kayali F, Olson RE, Milford CE. Pulmonary thromboembolism in Asians/Pacific Islanders in the United States: analysis of data from the National Hospital Discharge Survey and the United States Bureau of the Census. Am J Med 2004;116:435-442.

36. Steffen LM, Folsom AR, Cushman M, Jacobs DR Jr, Rosamond WD. Greater fish, fruit, and vegetable intakes are related to lower incidence of venous thromboembolism: the Longitudinal Investigation of Thromboembolism Etiology. Circulation 2007;115:188-195.

37. Sam JJ, Bernstein CN, Razik R, Thanabalan R, Nguyen GC. Physicians' perceptions of risks and practices in venous thromboembolism prophylaxis in inflammatory bowel disease. Dig Dis Sci 2013;58:46-52.

38. Ra G, Thanabalan R, Ratneswaran S, Nguyen GC. Predictors and safety of venous thromboembolism prophylaxis among hospitalized inflammatory bowel disease patients. J Crohns Colitis 2013;7:e479-e485.

39. Tinsley A, Naymagon S, Trindade AJ, Sachar DB, Sands BE, Ullman TA. A survey of current practice of venous thromboembolism prophylaxis in hospitalized inflammatory bowel disease patients in the United States. J Clin Gastroenterol 2013;47:e1-e6.

40. Papa A, Papa V, Marzo M, et al. Prevention and treatment of venous thromboembolism in patients with IBD: a trail still climbing. Inflamm Bowel Dis 2015;21:1204-1213.

41. Nylund CM, Goudie A, Garza JM, Crouch G, Denson LA. Venous thrombotic events in hospitalized children and adolescents with inflammatory bowel disease. J Pediatr Gastroenterol Nutr 2013;56:485-491.

42. Papa A, Gerardi V, Marzo M, Felice C, Rapaccini GL, 
Gasbarrini A. Venous thromboembolism in patients with inflammatory bowel disease: focus on prevention and treatment. World J Gastroenterol 2014;20:3173-3179.

43. Nicolaides S, Vasudevan A, Langenberg DV. Inflammatory bowel disease and superior mesenteric artery thromboembolism. Intest Res 2020;18:130-133.

44. Imbrizi MR, Magro DO, Secundo TM, et al. Hypoalbuminemia as a risk factor for thromboembolic events in inflammatory bowel disease inpatients. Intest Res 2019;17:63-69.

45. Liu J, Gao X, Chen Y, et al. Incidence and risk factors for venous thrombosis among patients with inflammatory bowel disease in China: a multicenter retrospective study. Intest Res 2021;19:313-322.

46. Kaddourah O, Numan L, Jeepalyam S, Abughanimeh O, Ghanimeh MA, Abuamr K. Venous thromboembolism prophylaxis in inflammatory bowel disease flare-ups. Ann Gastroenterol 2019;32:578-583.

47. Goto S, Haas S, Ageno W, et al. Assessment of outcomes among patients with venous thromboembolism with and without chronic kidney disease. JAMA Netw Open 2020;3:e2022886

48. Sarlos P, Szemes K, Hegyi P, et al. Steroid but not biological therapy elevates the risk of venous thromboembolic events in inflammatory bowel disease: a meta-analysis. J Crohns Colitis 2018;12:489-498.

49. Johannesdottir SA, Horváth-Puhó E, Dekkers OM, et al. Use of glucocorticoids and risk of venous thromboembolism: a nationwide population-based case-control study. JAMA Intern Med 2013;173:743-752.

50. van der Pas R, Leebeek FW, Hofland LJ, de Herder WW, Feelders RA. Hypercoagulability in Cushing's syndrome: prevalence, pathogenesis and treatment. Clin Endocrinol (Oxf) 2013;78:481-488.

51. Ananthakrishnan AN, Donaldson T, Lasch K, Yajnik V. Management of inflammatory bowel disease in the elderly patient: challenges and opportunities. Inflamm Bowel Dis 2017;23:882-893 